\title{
Adaptação transcultural na tradução do questionário "Quality of Life in Swallowing Disorders (SWAL-QOL)" para o português do Brasil
}

\section{Cross-cultural adaptation in the translation of the questionnaire "Quality of Life in Swallowing Disorders (SWAL-QOL)" into Brazilian Portuguese}

Leila Maria Gumushian Felipini* Elton Geraldo de Lacerda Prado**

Resumo: Este estudo tem como objetivo demonstrar a importância da adaptação transcultural em textos científicos, principalmente em questionários da área da saúde. Para tanto, utilizamos alguns itens do questionário "Quality of Life in Swallowing Disorders - SWAL-QOL” (FELIPINI 2016) e suas respectivas traduções,

* Docente da Universidade do Sagrado Coração.

** Bacharel pela Universidade do Sagrado Coração. 
síntese e final, a fim de exemplificar as situações em que a adaptação ao públicoalvo é de extrema relevância. Os itens analisados foram classificados como "não equivalentes" por pelo menos um dos membros do comitê de peritos, no que diz respeito às equivalências experimental e conceitual. A base teórica deste estudo abrangeu conceitos da área da tradução e da área da saúde. Foi possível demostrar que a tradução é um processo de negociação entre culturas, conforme indica Bassnett (2003).

Palavras-chave: tradução; adaptação transcultural; questionário da área da saúde.

Abstract: This study aims to demonstrate the importance of the cross-cultural adaptation in scientific texts mainly in health questionnaires. To do so, we used some items of the "SWAL-QOL - Quality of Life in Swallowing Disorders" questionnaire (FELIPINI 2016) and their respective translations, synthesis and final, in order to exemplify the situations in which the adaptation to the target public is extremely relevant. The analyzed items were classified as "non-equivalent" by at least one of the members of the committee of experts, concerning the experimental and conceptual equivalences. The theoretical basis of this study covers concepts in the fields of both translation and health care. It was possible to demonstrate that translation is a process of negotiation between cultures, according to Bassnett (2003).

Keywords: Translation; Cross-Cultural Adaptation; Health Questionnaire. 
FELIPINI, L. M. G. - Adaptação transcultural na tradução do questionário "Quality of Life in Swallowing Disorders (SWAL-QOL)" para o português do Brasil

\section{Introdução}

A tradução está presente em diversas situações de comunicação há muitos e muitos anos; hoje, porém, esta presença se dá de forma contundente e necessária, uma vez que vivemos a era do crescimento acelerado da tecnologia em um mundo globalizado que dissemina imediatamente todo e qualquer tipo de informação, seja esta escrita, falada ou visual.

Considerando o imenso número de línguas e dialetos falados ao redor do planeta, a tradução é a ponte que, assim como um barco, leva uma pessoa de um lado ao outro de um rio. Desta forma, independentemente da área, para tornar a informação acessível a um ou mais públicos específicos, a atividade tradutória é fundamental.

$\mathrm{Na}$ área da saúde, em específico, a tradução promove a disseminação de estudos nas mais diversas vertentes, possibilitando, por exemplo, o uso eficaz de protocolos e questionários utilizados para diagnosticar e avaliar resultados de tratamentos. No que diz respeito aos textos científicos, as pessoas comumente acreditam que não há necessidade de adaptar conteúdo ao traduzir de um idioma para o outro. Entretanto, esse pensamento é errôneo, pois sempre que há aspectos de diferentes culturas envolvidos, haverá em algum momento a necessidade de promover adaptações culturais. Um exemplo são os questionários utilizados para diagnóstico e acompanhamento da evolução de determinadas doenças.

A maioria desses questionários é escrita em língua inglesa para ser utilizada com falantes desse idioma. Neste caso, a adaptação é fundamental uma vez que a cultura da língua de partida tem características próprias, que a diferem da cultura de língua de chegada, e o tradutor é o responsável pelo papel de mediador entre as culturas de partida e de chegada, além de facilitador da compreensão do texto. 
FELIPINI, L. M. G. - Adaptação transcultural na tradução do questionário "Quality of Life in Swallowing Disorders (SWAL-QOL)" para o português do Brasil

Considerando o exposto, este estudo tem como objetivo demonstrar a necessidade da adaptação cultural em textos científicos. Para isso, identificamos e descrevemos algumas das adaptações culturais realizadas no processo de tradução e adaptação transcultural do questionário "Quality of Life in Swallowing Disorders (SWAL-QOL)" para o português do Brasil (FELIPINI 2016), contribuindo para descontruir a ideia de que basta ao tradutor, em textos científicos, traduzir de forma literal.

Desta forma, desenvolvemos uma análise comparativa entre termos presentes no questionário original em língua inglesa, na versão síntese em língua portuguesa e na versão final do questionário em língua portuguesa.

Nossa análise teve como fundamentação teórica conceitos utilizados nos estudos da tradução, de acordo com teóricos como Robinson (2002), e nos estudos da área da saúde que envolvem processos de tradução e adaptação transcultural, de acordo com Guillemin, Bombardier e Beaton (1993) e Beaton et al. (2000).

\section{Aporte teórico}

Não existe um consenso que delimite a tradução a uma só teoria, mas há definições propostas por teóricos que contribuem para a compreensão da atividade tradutória ou para a avaliação de um texto traduzido:

[...] ainda não existe nenhuma teoria unificada da tradução no sentido técnico de "um conjunto coerente de proposições gerais usadas como princípios para explicar uma classe de fenômenos", mas existem algumas "teorias" no sentido lato de "um conjunto de princípios úteis para compreender a natureza da tradução ou para estabelecer critérios de avaliação de um texto traduzido". (NIDA 1993: 155). 
FELIPINI, L. M. G. - Adaptação transcultural na tradução do questionário "Quality of Life in Swallowing Disorders (SWAL-QOL)" para o português do Brasil

De acordo com Rónai (1981), pessoas com menor entendimento sobre o ato tradutório o julgam como sendo uma mera transposição de palavras, na qual o tradutor, conhecedor de um par de línguas, substitui sentenças da língua A por equivalentes da língua B. Porém, o teórico afirma que traduzir consiste na compreensão de que algumas palavras e frases estão sujeitas a ambiguidades, dando sentido ao texto somente quando associadas umas com as outras, e não isoladamente.

Complementando a passagem anterior, Arrojo (1986) afirma que a operação tradutória produz significados e que caminhos mais fáceis nessa atividade não seriam a melhor alternativa, pois sendo a tradução um processo de leitura e interpretação de um determinado contexto linguístico, a compreensão de cada tradutor resulta de maneira particular na escolha dos equivalentes linguísticos do outro idioma.

A questão cultural é acrescentada à discussão do processo tradutório uma vez que esse processo é visto como envolvendo negociação entre culturas:

\begin{abstract}
A tradução não é somente a transferência de textos de uma língua para outra - ela é hoje corretamente vista como um processo de negociação entre textos e entre culturas, um processo em que ocorrem todos os tipos de transações mediadas pela figura do tradutor. (BASSNETT 2003: 9)
\end{abstract}

De acordo com Robinson (2002), alguns textos contêm termos tão pertinentes a uma cultura específica que tornam a transposição uma tarefa extremamente reflexiva. Há grandes debates acerca desse assunto, como quando parafrasear ou quando usar um equivalente local que represente esse significante ou também quando criar e transcrever uma nova palavra.

Mona Baker caracteriza as palavras culturalmente determinadas como palavras utilizadas para expressar conceitos específicos da cultura de partida e, portanto, desconhecidos na cultura de chegada. Segundo Baker (1992), um 
FELIPINI, L. M. G. - Adaptação transcultural na tradução do questionário "Quality of Life in Swallowing Disorders (SWAL-QOL)" para o português do Brasil

determinado conceito pode ser "abstrato ou concreto, estar relacionado a uma crença religiosa, um costume social ou até mesmo a um tipo de comida" (apud HATJE-FAGGION 2011: 73).

Newmark (apud HATJE-FAGGION 2011: 75) propõe uma classificação dos referentes culturais, separados em: ecologia (plantas, ventos locais, montanhas, planícies, gelo, etc.); cultura material e artefatos (comida, roupas, casas, cidades, transporte e comunicações); cultura social (trabalho e lazer); organizações, costumes, atividades, procedimentos, conceitos, ideias (políticas, sociais, legais, religiosas, artísticas); e gostos e hábitos.

Robinson (2002) afirma ainda que há uma grande necessidade de transpor as barreiras culturais porque estas existem e estão presentes não só quando contrastadas umas com as outras, como no caso de países diferentes, mas também dentro de um só contexto geográfico. Buscamos constantemente quebrar essas barreiras culturais, mesmo sendo uma tarefa difícil a de irromper os limites de outras culturas; sendo necessário, de acordo com o teórico, ter pele escura para de fato saber como vive uma pessoa de pele escura ou viver em um país desenvolvido para saber como é viver em tal país. Porém, "continuamos tentando entender, criar uma ponte entre as lacunas de comunicação existentes entre indivíduos e grupos. É isso que fazemos". (ROBINSON 2002: 309).

Discorrendo também sobre a questão cultural, Nord (2005) ressalta que o receptor de um texto traduzido, por ter crescido em outra cultura, possui uma vivência de mundo e perspectiva diferente sobre as coisas, além de uma "experiência textual" que o fará ter uma interpretação muito pessoal sobre a leitura do texto traduzido.

Para que consigamos defrontar essas diferenças culturais, há na tradução uma modalidade chamada adaptação, a qual indica uma assimilação cultural. Segundo Aubert (1998), a adaptação estabelece uma equivalência parcial, considerada suficiente para o segmento textual em questão. 
FELIPINI, L. M. G. - Adaptação transcultural na tradução do questionário "Quality of Life in Swallowing Disorders (SWAL-QOL)" para o português do Brasil

Teóricos da área da saúde também defendem a necessidade da adaptação de conteúdo, mesmo em textos científicos. Guillemin, Bombardier e Beaton (1993), por exemplo, explicam que a adaptação transcultural é definida não só pela tradução literal de sentenças de um idioma para o outro, mas também pela adaptação dessas sentenças para o melhor entendimento de um público leitor de outra cultura que não à qual 0 instrumento foi inicialmente proposto. Teóricos como Reichenheim e Moraes (2007) recomendam que o procedimento de adaptação seja um processo meticuloso de sintonização, que contemple o contexto cultural e o estilo de vida do público-alvo da versão.

Barbosa (2004) ressalta que, quando não existe um termo na realidade extralinguística do público ao qual a tradução se destina, o procedimento de adaptação, extremo na tradução, se faz necessário.

Visando essa adaptação transcultural, diretrizes são propostas por Guillemin, Bombardier e Beaton (1993) e por Beaton et al. (2000), que recomendam etapas para que o processo tradutório alcance não apenas uma equivalência semântica, mas também idiomática, experimental e conceitual entre o instrumento original e sua tradução.

De acordo com Beaton et al. (2000), a equivalência semântica se refere à igualdade no significado das palavras, já que, por vezes, uma palavra em determinado contexto pode adquirir um significado diferente. A equivalência semântica cria um fator facilitador no texto, descomplicando questões textuais em que há palavras que podem ser usadas em diversos contextos por ter múltiplos significados. Como afirma outro teórico, "as palavras não possuem sentido isoladamente, mas dentro de um contexto, e por estarem dentro desse contexto". (Rónal 1981: 17).

Ainda de acordo com Beaton et al. (2000), a equivalência idiomática se refere às expressões idiomáticas e termos geralmente usados no cotidiano, palavras normalmente tidas como informais, por exemplo, os coloquialismos. 
FELIPINI, L. M. G. - Adaptação transcultural na tradução do questionário "Quality of Life in Swallowing Disorders (SWAL-QOL)" para o português do Brasil

Neste caso, há a necessidade de substituição de sentença de uma língua por outra equivalente.

A equivalência experimental, também de acordo com Beaton et al. (2000), se dá quando há, em determinado contexto linguístico, um hábito qualquer de uma cultura que não é comumente conhecido ou vivenciado em outra cultura.

Por fim, a equivalência conceitual, ainda segundo o teórico citado nas equivalências anteriores, Beaton et. al. (2000), a palavra existe nas duas línguas, mas o conceito atribuído a ela é diferente. Por exemplo, o futebol (American soccer) para os brasileiros é diferente do futebol (American soccer) para os americanos. Para eles, nosso futebol é apenas um esporte, para os brasileiros é uma paixão, como é para eles o American Football. Essa assimilação inserida em um texto torna clara a ideia de equivalência conceitual.

Tendo exposto a teoria que embasa este estudo, passamos a analisar a tradução.

\section{Metodologia}

Para demonstrar as adaptações culturais realizadas no processo de tradução e adaptação transcultural do questionário SWAL-QOL (FELIPINI 2016), comparamos o conteúdo do questionário original às escolhas tradutórias presentes na versão síntese e na versão final do questionário. Para isso, utilizamos como objetos de estudo (1) o documento da reunião do comitê de peritos (estágio 4 - comitê de peritos) e (2) a versão final do questionário, ambos da pesquisa intitulada "Tradução e adaptação transcultural para a língua portuguesa do Brasil dos questionários 'Quality of Life in Swallowing 
FELIPINI, L. M. G. - Adaptação transcultural na tradução do questionário "Quality of Life in Swallowing Disorders (SWAL-QOL)" para o português do Brasil

Disorders (SWAL-QOL)' e 'Quality of Care in Swallowing Disorders (SWALCARE)' para idosos com disfagia neurogênica" (FELIPINI 2016).

Essa tradução do SWAL-QOL foi desenvolvida durante o doutorado da Profa. Dra. Leila Maria Gumushian Felipini pela Faculdade de Odontologia de Bauru da Universidade de São Paulo, com a colaboração dos tradutores Gustavo Inheta Baggio, Patrícia Viana Belam e Cássia de Souza Pardo-Fanton, professores da Universidade do Sagrado Coração, além de dois nativos americanos, uma fonoaudióloga e a pesquisadora.

O procedimento de tradução e adaptação transcultural do SWAL-QOL seguiu as diretrizes propostas por Beaton et al. (2000): (1) traduções; (2) síntese das traduções; (3) retrotraduções; (4) comitê de peritos; (5) teste da versão prévia; (6) submissão dos documentos deste processo para um comitê de acompanhamento.

No primeiro estágio, duas traduções foram elaboradas por tradutores distintos; no segundo estágio, essas duas traduções foram analisadas, e uma versão síntese foi estabelecida durante uma reunião entre os tradutores e um juiz neutro; no terceiro estágio, essa versão síntese foi retrotraduzida para a língua inglesa por dois falantes de língua inglesa; no quarto estágio, houve uma nova reunião envolvendo os dois tradutores, os dois retrotradutores e outros especialistas que estabeleceram a versão prévia a ser testada; no quinto estágio, aconteceram os testes e as adequações necessárias para que uma versão final em língua portuguesa fosse estabelecida. Todo o processo foi documentado e acompanhado pela pesquisadora e sua co-orientadora, a Profa. Dra. Giédre Berretin-Felix.

Para escolhermos os termos analisados neste estudo, recorremos à classificação dada pelos membros do comitê de peritos (etapa 4 do processo tradutório) que aplicaram as notas (-1) não equivale; (0) equivale e (1) equivale muito aos itens da versão síntese da tradução do questionário. Para essa classificação, os membros do comitê foram orientados a comparar o conteúdo do questionário original e o conteúdo da versão síntese 
FELIPINI, L. M. G. - Adaptação transcultural na tradução do questionário "Quality of Life in Swallowing Disorders (SWAL-QOL)" para o português do Brasil

considerando as equivalências semântica, idiomática, experimental e conceitual. Mais especificamente, optamos por analisar os itens classificados como não equivalentes (-1).

Participaram deste comitê os tradutores responsáveis pela Tradução 1, Tradução 2 e Retrotradução 1, além de um juiz (perito em Letras), um profissional da área da saúde (fonoaudiólogo) e um metodologista. 0 tradutor responsável pela Retrotradução 2 enviou suas contribuições por escrito pela pesquisadora responsável pela pesquisa (FELIPINI 2016).

Uma vez que o objetivo deste estudo foi demonstrar as adaptações culturais realizadas no processo de tradução e adaptação transcultural descrito acima, optamos por analisar os excertos classificados como não demonstrando equivalência experimental ou conceitual.

\section{Análise}

As análises estão estruturadas de acordo com as equivalências experimental e conceitual.

Primeiramente, apresentamos exemplos de itens classificados como não contendo equivalência experimental. De acordo com Beaton et. al. (2000), isso se dá quando em determinado contexto linguístico há um hábito qualquer de uma cultura que não é comumente conhecido ou vivenciado em outra cultura.

Durante a reunião do comitê de peritos, um dos itens traduzidos apontados como não tendo equivalência experimental foi o equivalente sugerido na versão síntese, suco de goiaba, para o original, tomato juice: 
FELIPINI, L. M. G. - Adaptação transcultural na tradução do questionário "Quality of Life in Swallowing Disorders (SWAL-QOL)" para o português do Brasil

\begin{tabular}{|l|l|}
\hline ORIGINAL & $\begin{array}{l}\text { Circle this if the majority of liquids you drink are thick, like } \\
\text { tomato juice or apricot nectar. }\end{array}$ \\
\hline SÍNTESE & $\begin{array}{l}\text { A maioria dos líquidos que você está ingerindo tem } \\
\text { consistência espessa, como suco de goiaba ou néctar de } \\
\text { pêssego. }\end{array}$ \\
\hline FINAL & $\begin{array}{l}\text { A maioria dos líquidos que você bebe tem consistência } \\
\text { espessa, como suco de manga ou néctar de pêssego. }\end{array}$ \\
\hline
\end{tabular}

Tabela 1

O suco de tomate é comumente consumido entre os americanos, público-alvo do questionário original. Entretanto, no Brasil, o seu consumo não é tão comum. Assim, buscando retratar a realidade dos hábitos alimentares dos brasileiros, a tradução síntese trouxe "suco de goiaba" como equivalente para o suco de tomate.

De acordo com Newmark (apud HATJE-FAGGION 2011), assim como roupas, casas, cidades, transportes e comunicação, os alimentos são considerados referentes culturais.

O equivalente "suco de goiaba" proposto na versão síntese já apresentava uma adequação à realidade dos brasileiros, entretanto a fonoaudióloga presente na reunião classificou a tradução deste item como não apresentando equivalência experimental, uma vez que o público-alvo do estudo era composto apenas por idosos com disfagia e que, portanto, a questão era encontrar um líquido cuja consistência fosse mais próxima à do suco de tomate dos EUA.

Para que possamos entender e assimilar com objetividade as adaptações feitas para a língua portuguesa do questionário SWAL-QOL, devemos entender do que se trata a disfagia. Segundo o site do hospital SírioLibanês (2016), disfagia é uma condição comum em pacientes com doenças neurológicas, como pessoas acometidas por paralisia cerebral, Parkinson, derrame e em pacientes com tumores ou traumas da boca ou garganta. 0 paciente com disfagia encontra muita dificuldade ao engolir. Dessa forma, a 
FELIPINI, L. M. G. - Adaptação transcultural na tradução do questionário "Quality of Life in Swallowing Disorders (SWAL-QOL)" para o português do Brasil

doença compromete a deglutição e causa desnutrição e desidratação, além de possíveis problemas como o de aspirar o alimento em direção aos pulmões.

De acordo com Carrara-de Angelis e Bandeira (2009), a deglutição compreende desde o recebimento do alimento pela boca até a sua passagem para o estômago e é uma função fundamental para que se possa ter uma vida social com qualidade. As autoras também relatam que a condição da disfagia leva a limitações na alimentação de uma ou mais consistências e volumes.

De acordo com McHorney et al. (2000), a disfagia afeta a mais básica das funções humanas que é a de comer e beber, e essa incapacidade de se alimentar corretamente não é uma condição de vida aceitável.

Logo a seguir vemos as figuras dos respectivos sucos citados no questionário:

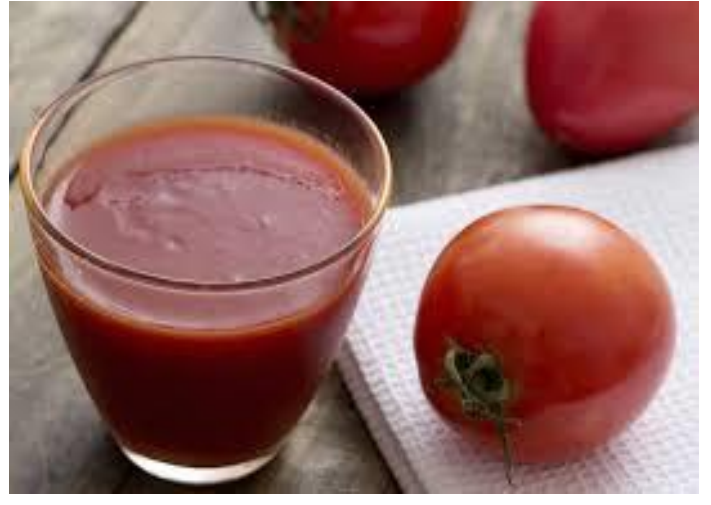

Figura 1 - suco de tomate

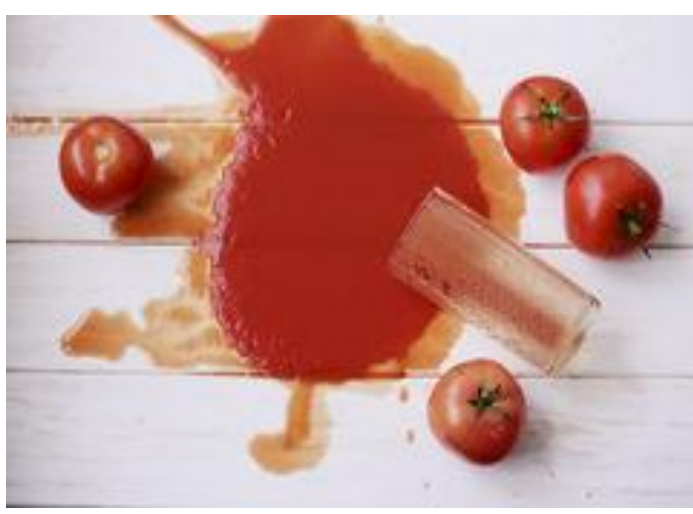

Figura 2 - consistência do suco de tomate 
FELIPINI, L. M. G. - Adaptação transcultural na tradução do questionário "Quality of Life in Swallowing Disorders (SWAL-QOL)" para o português do Brasil

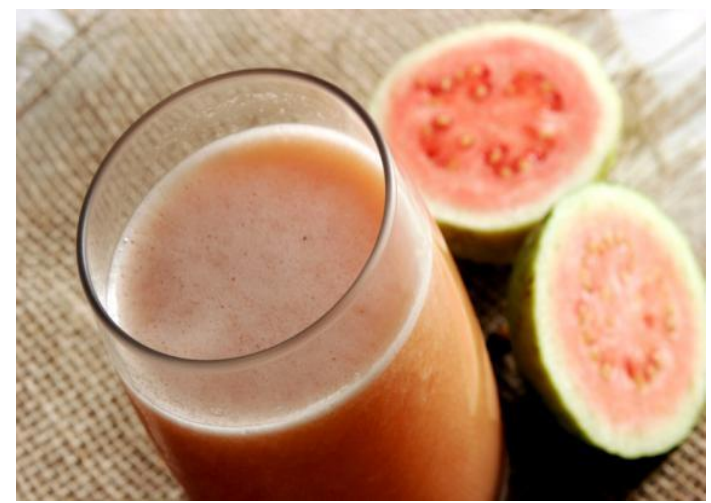

Figura 3 - suco de goiaba

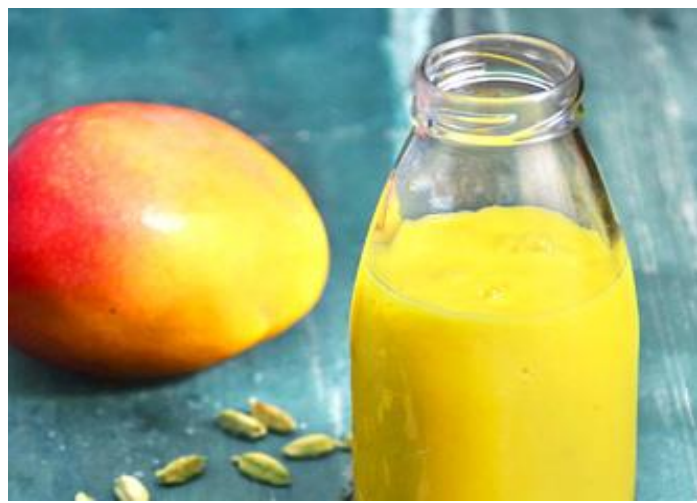

Figura 4 - suco de manga

Desta forma, considerando que tanto o "suco de goiaba" quanto o "suco de manga" são mais comuns entre os hábitos alimentares dos brasileiros do que o suco de tomate, mas não possuem a mesma consistência, a fonoaudióloga argumentou que o suco que mais se aproxima do de tomate seria o "suco de manga" por ambos apresentarem consistência mais próxima. A consistência de cada alimento é muito relevante, uma vez que o questionário avalia justamente a deglutição de pacientes com disfagia.

Outro item do questionário classificado como não apresentando equivalência experimental foi o equivalente sugerido na versão síntese, "mousse", para o original pudding:

\begin{tabular}{|l|l|}
\hline ORIGINAL & $\begin{array}{l}\text { C. Circle this one if you are eating food that is put through a blender } \\
\text { or food processor or anything that is like pudding or pureed foods. }\end{array}$ \\
\hline SÍNTESE & $\begin{array}{l}\text { C. Você come alimentos batidos no liquidificador ou processador, ou } \\
\text { alimentos como mousse ou purê. }\end{array}$ \\
\hline FINAL & $\begin{array}{l}\text { C. Você come alimentos batidos no liquidificador ou no processador, } \\
\text { ou alimentos como mingau ou papa. }\end{array}$ \\
\hline
\end{tabular}

Tabela 2

Para Barbosa (2004), a adaptação é o extremo da tradução e ocorre quando a situação a que se refere o texto na língua original não existe na realidade da língua traduzida. Desta forma, os tradutores, juntamente com o 
FELIPINI, L. M. G. - Adaptação transcultural na tradução do questionário "Quality of Life in Swallowing Disorders (SWAL-QOL)" para o português do Brasil

perito em Letras, chegaram a um consenso, optando pelo referente cultural mousse, na versão síntese, para representar pudding.

Pudding, como podemos ver a seguir na figura 5, apesar de ser uma sobremesa, não apresenta a mesma consistência do pudim da figura 6. Dessa forma, "mousse", presente na figura 7 , foi a sobremesa usada na versão síntese, com o intuito de substituir a sobremesa mencionada no questionário original. Porém, o retrotradutor, presente no comitê de peritos, chamou a atenção para o fato do mousse não ser o equivalente adequado, uma vez que, como podemos observar e comparar nas figuras 5 e 7 , o mousse não substitui o pudding com exatidão, pois sua consistência é mais espessa.

Sendo assim, os membros do comitê de peritos optaram por "mingau", figura 8 , por ser um equivalente que substitui com mais objetividade 0 referente cultural original, uma vez que ambos apresentam a mesma textura e a mesma consistência. Além disso, o "mingau" é mais adequado por ser um alimento mais comum a toda a população brasileira. 0 receptor de um texto traduzido, por ter crescido em outra cultura, como afirma Nord (2005), possui uma vivência de mundo e perspectiva diferente sobre as coisas, além de uma "experiência textual" que o fará ter uma interpretação muito pessoal sobre a leitura do texto traduzido.

Levando em conta que o questionário foi desenvolvido como ferramenta de avaliação de pacientes idosos com disfagia, não basta ao tradutor, como mediador entre textos, simplesmente encontrar um correlato linguístico. No caso do questionário SWAL-QOL, que é da área da saúde, o comitê de peritos se atentou ao termo usado no questionário original e fez uso do equivalente que manteve a função de avaliação do questionário com os pacientes idosos brasileiros com disfagia.

As imagens a seguir facilitam a compreensão. 
FELIPINI, L. M. G. - Adaptação transcultural na tradução do questionário "Quality of Life in Swallowing Disorders (SWAL-QOL)" para o português do Brasil

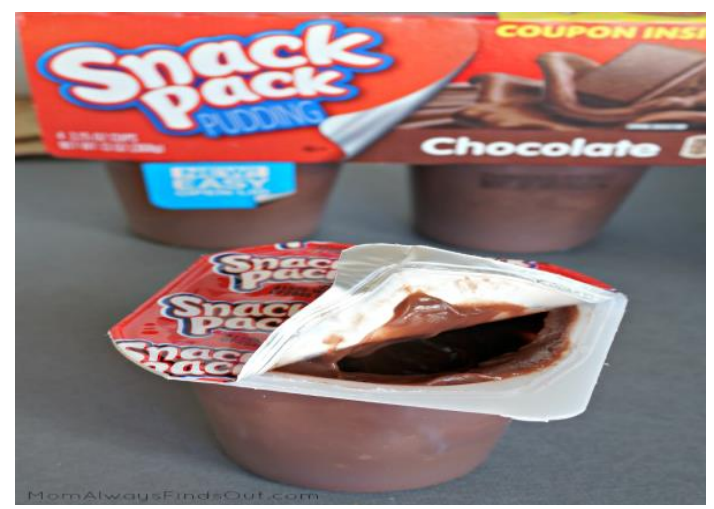

Figura 5 - Pudding

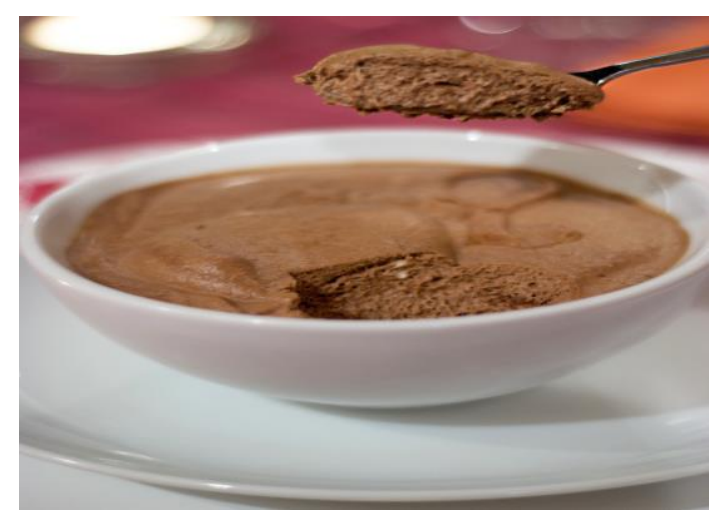

Figura 7 - Mousse

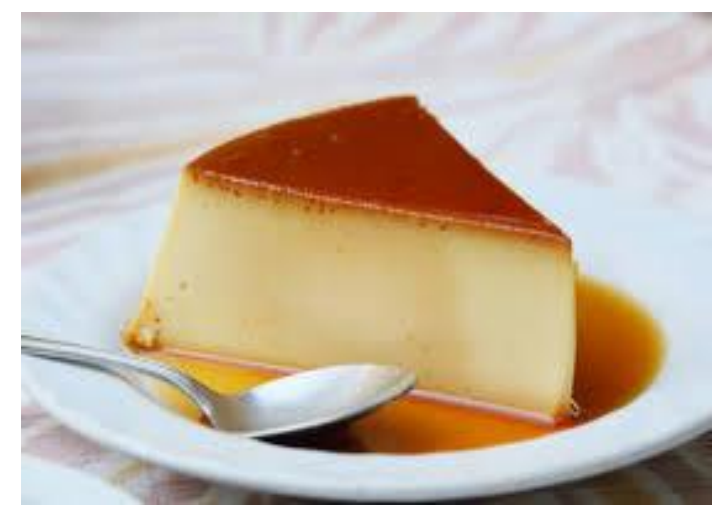

Figura 6 - Pudim

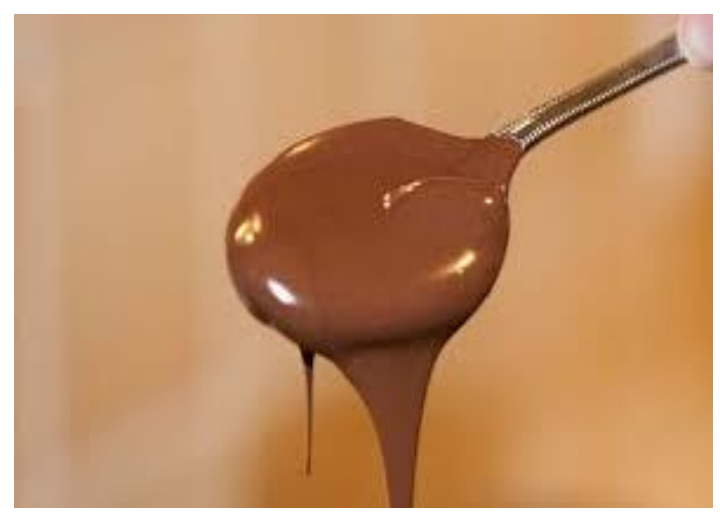

Figura 8 - Mingau

Como pudemos ver nas imagens acima, o pudim referente à cultura americana é normalmente comercializado em pequenos recipientes, e sua consistência tem bem menos solidez do que o pudim consumido no Brasil. $\mathrm{Na}$ deglutição, ao ingerirmos ambos os alimentos, notamos com clareza a diferença da consistência de cada um, o que influi diretamente sobre a dificuldade ou não da sua ingestão, uma vez que pessoas com disfagia respondem de maneira diferente de outras que não são acometidas por essa condição.

Outro item que o comitê de peritos avaliou como sem equivalência experimental foi "ensopados" como tradução para o original, casseroles. Trata-se de outro termo que é classificado, de acordo com Newmark (apud HATJE-FAGGION 2011), como sendo um referente cultural. 
FELIPINI, L. M. G. - Adaptação transcultural na tradução do questionário "Quality of Life in Swallowing Disorders (SWAL-QOL)" para o português do Brasil

\begin{tabular}{|l|l|}
\hline ORIGINAL & $\begin{array}{l}\text { B. Circle this one if you are eating soft, easy to chew foods like } \\
\text { casseroles, canned fruits, soft cooked vegetables, ground meat, or } \\
\text { cream soups. }\end{array}$ \\
\hline SÍNTESE & $\begin{array}{l}\text { B. Você está comendo alimentos macios, fáceis de mastigar como } \\
\text { ensopados, frutas em conserva, legumes bem cozidos, carne moída } \\
\text { ou sopas cremosas. }\end{array}$ \\
\hline FINAL & $\begin{array}{l}\text { B. Você come alimentos macios, fáceis de mastigar como massas, } \\
\text { frutas em conserva, legumes bem cozidos, carne moída ou sopas } \\
\text { cremosas. }\end{array}$ \\
\hline
\end{tabular}

Tabela 3

Naturalmente, as adaptações são necessárias quando o referente em questão no texto original não faz parte da cultura-alvo, como no caso do questionário SWAL-QOL, em que o público-alvo era os brasileiros.

A tradução para casseroles de acordo com o site Tecla SAP (2013) é “cozido", que, de acordo com Michaelis (2016), é um prato que reúne diversos tipos de carne, batatas, legumes, verduras etc. fervido. Na versão síntese, tentando melhor substituir o referente casseroles, foi feita a escolha pelo termo "ensopados". Apesar de ser um prato muito comum na cultura brasileira, os ensopados não podem substituir o referente americano, especificamente no questionário da área da saúde, pois, como já mencionado em outras análises, o questionário visa analisar a qualidade de vida de pessoas com disfagia, suas restrições alimentares, suas dificuldades em consumirem determinados alimentos, razão pela qual as adaptações feitas devem ser rigorosas nesse sentido. Por serem pratos compostos por muitos ingredientes, ao pensar em ensopados ou cozidos, pode vir à mente diferentes pratos, tornando a questão nada objetiva. Novamente, o participante do comitê de peritos que chamou a atenção para essa inadequação foi o retrotradutor, que afirmou não haver um correspondente na culinária local.

As figuras 9 e 10 representam a variedade de ensopados na culinária brasileira. Assim, para encontrar um equivalente que contemplasse não 
FELIPINI, L. M. G. - Adaptação transcultural na tradução do questionário "Quality of Life in Swallowing Disorders (SWAL-QOL)" para o português do Brasil

apenas a equivalência semântica, mas também a experimental, o comitê optou por "massas", uma vez que a consistência das massas (figuras 11 e 12), em sua grande maioria, é muito parecida com o prato americano casserole, além de o brasileiro ter o costume de se alimentar de massa. Esse equivalente atinge, portanto, o objetivo do questionário tanto de avaliar com exatidão a presença ou não de disfagia quanto de ser um equivalente experimental para a cultura brasileira.

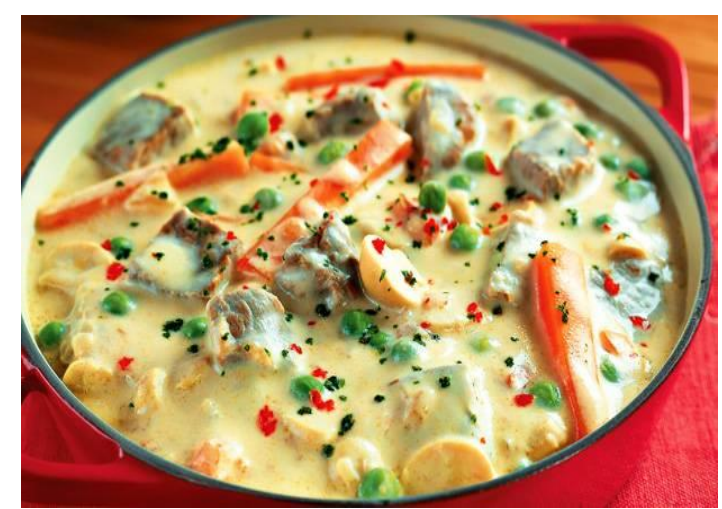

Figura 9 - Ensopado

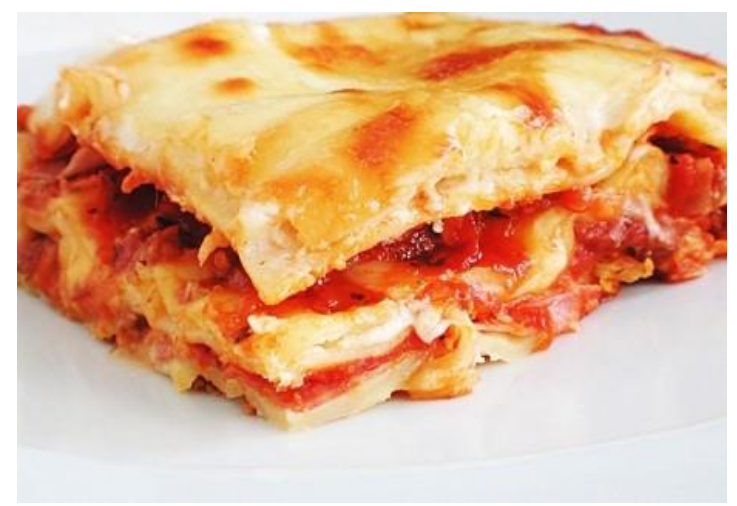

Figura 11 - Massas

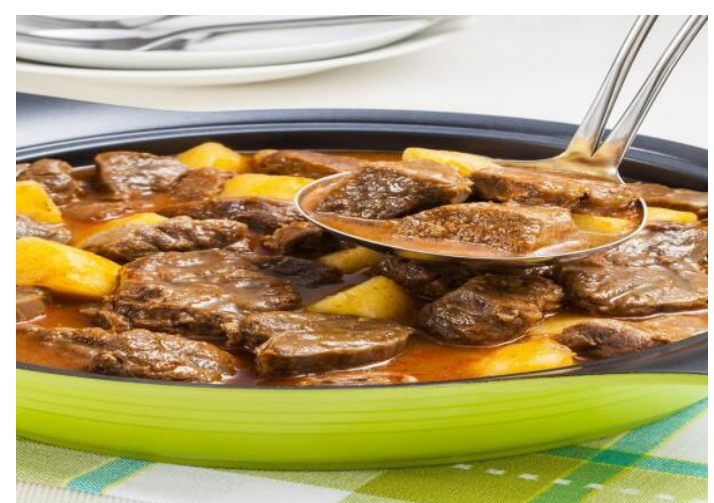

Figura 10 - Ensopado

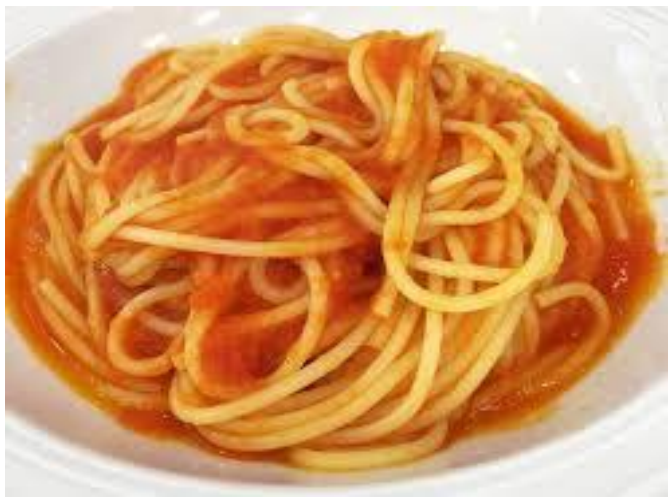

Figura 12 - Massas

Conforme descrito no início da análise, tendo analisado os itens que não apresentaram equivalência experimental, passamos a analisar os itens classificados como não apresentando a equivalência conceitual. De acordo com Beaton et al. (2000), trata-se de uma palavra existente nas duas línguas, mas cujo conceito atribuído a ela é diferente nessas línguas. 
FELIPINI, L. M. G. - Adaptação transcultural na tradução do questionário "Quality of Life in Swallowing Disorders (SWAL-QOL)" para o português do Brasil

O questionário SWAL-QOL também continha perguntas gerais, uma dais quais questionava em qual classificação étnica e racial os idosos se identificavam. Uma das opções de resposta era Black or African American, but not Hispanic or Latino.

\begin{tabular}{|l|l|}
\hline ORIGINAL & Black or African-American, but not Hispanic or Latino \\
\hline SÍNTESE & Negro \\
\hline FINAL & Preto \\
\hline
\end{tabular}

Tabela 4

É possível observar que, já na tradução síntese, a segunda parte da opção de resposta foi excluída, uma vez que não se adequa a realidade do povo brasileiro, já que somos todos latinos, moradores da América Latina.

No que diz respeito à primeira parte da opção de resposta, nos Estados Unidos, o mais comum é fazer uso do termo afro-americano para designar pessoas cuja cor de pele é escura. De acordo com o site UOL (2013), não existe uma classificação internacional para raças ou para etnias e os conceitos são diferentes conforme a história de cada povo. No Brasil, ainda muito se discute sobre isso e, segundo o site UOL (2013), o IBGE (Instituto Brasileiro de Geografia e Estatística) usa o termo preto como classificação de cor no Brasil. Seguindo o padrão do IBGE, o comitê optou pelo uso do termo "preto" na versão final.

Outro termo classificado como não apresentando equivalência conceitual entre as versões síntese e original é o termo "interação" para o original my role.

\begin{tabular}{|l|l|}
\hline ORIGINAL & $\begin{array}{l}\text { My role with family and friends has changed because of my } \\
\text { swallowing problem. }\end{array}$ \\
\hline SÍNTESE & $\begin{array}{l}\text { Minha interação com a família e os amigos mudou devido ao meu } \\
\text { problema de deglutição. }\end{array}$ \\
\hline
\end{tabular}


FELIPINI, L. M. G. - Adaptação transcultural na tradução do questionário "Quality of Life in Swallowing Disorders (SWAL-QOL)" para o português do Brasil

\begin{tabular}{|l|l|}
\hline FINAL & $\begin{array}{l}\text { Minha função na família e com os amigos mudou devido ao meu } \\
\text { problema de deglutição. }\end{array}$ \\
\hline
\end{tabular}

Tabela 5

O conceito da palavra "interação", escolha da versão síntese, e de role, da versão original, não é o mesmo. Dessa forma, houve a alteração, optando por uma palavra que tivesse a mesma representatividade nos dois idiomas. De acordo com o dicionário Cambridge (2016), role é o papel que alguém ou alguma coisa tem em uma situação específica. Há algumas definições para "interação" no dicionário Michaelis (2016), que se referem ao conjunto de atividades realizadas entre os membros de uma comunidade; 0 contato entre indivíduos que convivem.

De acordo com as definições ditas acima, notamos a discrepância entre o conceito dessas duas palavras. A função de alguém é a importância deste perante uma situação familiar ou não, como um pai, por exemplo, o papel dele ou a função dele no âmbito familiar, a importância dele perante um filho. Já interação é como esse pai, por exemplo, desenvolve seu papel no âmbito familiar. Se fosse mantida a escolha da versão síntese, essa não causaria estranhamento por ser uma palavra comum, porém não apresentaria uma função equivalente ao referente da versão original.

Robinson (2002) afirma que alguns textos contêm termos tão pertinentes a uma cultura específica que tornam a transposição uma tarefa extremamente reflexiva. Daí a importância da presença de tradutores e de nativos neste processo de tradução e adaptação cultural.

Analisamos outro item do questionário contendo um termo sem equivalência conceitual entre as versões síntese e original.

ORIGINAL Social gatherings (like holidays or get-togethers) are not enjoyable because of my swallowing problem. 
FELIPINI, L. M. G. - Adaptação transcultural na tradução do questionário "Quality of Life in Swallowing Disorders (SWAL-QOL)" para o português do Brasil

\begin{tabular}{|l|l|}
\hline SÍNTESE & $\begin{array}{l}\text { Atividades sociais (férias ou reuniões com amigos) não são prazerosos } \\
\text { devido ao meu problema de deglutição. }\end{array}$ \\
\hline FINAL & $\begin{array}{l}\text { Reuniões sociais (passeios ou encontros) não são prazerosos devido ao } \\
\text { meu problema de deglutição. }\end{array}$ \\
\hline
\end{tabular}

Tabela 6

A escolha feita para a versão síntese “férias" não apresentava equivalência conceitual em relação à palavra holidays presente no questionário original. Dessa forma, o comitê de peritos optou por outro referente na versão final do questionário em língua portuguesa.

A tradução dada para holidays como "férias" é comum no inglês britânico; no inglês americano, por sua vez, dicionários como o Cambridge (2016) dão a "férias" a tradução de vacation. O mesmo dicionário traz também a palavra "feriados" como tradução para holidays. Como o questionário foi elaborado nos Estados Unidos, usar “férias" como equivalente na tradução não substituiria holidays. Assim, o comitê de peritos optou por “passeios" para representar o conceito de holidays na cultura brasileira. De acordo com o dicionário Cambridge (2016), “feriado” é um dia para celebrar ou relembrar um evento especial, quando muitas pessoas não vão à escola ou ao trabalho.

Os americanos celebram de diversas maneiras as datas especiais e muitos saem em passeio para celebrar ou simplesmente para aproveitar o dia de folga, conceitos que são semelhantes no Brasil. Manter o equivalente da versão síntese não atrapalharia a compreensão, porém não é o conceito que equivale ao da versão original.

\section{Considerações finais}


FELIPINI, L. M. G. - Adaptação transcultural na tradução do questionário "Quality of Life in Swallowing Disorders (SWAL-QOL)" para o português do Brasil

Considerando as análises feitas neste estudo, pudemos claramente perceber a importância da adaptação de referentes culturais em textos científicos, principalmente nos que visam diagnosticar ou avaliar tratamentos médicos, como os questionários. Para ressaltar a relevância das adaptações culturais, teóricos como Reichenheim e Moraes (2007) afirmam que o procedimento de adaptação deve contemplar o contexto cultural e estilo de vida da população-alvo da versão.

Fica claro que o uso apenas da tradução literal em questionários da área da saúde não é suficiente devido às diferenças existentes entre os contextos culturais do público-alvo do texto de partida e do público-alvo da tradução.

Para que se alcancem os resultados esperados de um questionário cuja função é avaliar a deglutição em pacientes com disfagia, faz-se necessário propor o uso de termos que substituam os referentes culturais da língua de partida por equivalentes que possibilitem o uso do questionário entre os brasileiros.

Com isso, concluímos que, mesmo em textos científicos, é essencial o uso de adaptação cultural, permitindo o uso correto dos textos traduzidos e possibilitando os mesmos resultados que o texto de partida pretendia, mas agora no público-alvo da tradução.

\section{Referências bibliográficas}

ARrojo, R. Oficina de tradução: a teoria na prática. São Paulo: Ática, 1986.

AUBERT, F. H. "Modalidades de tradução: teorias e resultados". In: TradTerm, São Paulo, v. 5, n. 1, 1998. pp. 99-128. Disponível em: 
FELIPINI, L. M. G. - Adaptação transcultural na tradução do questionário "Quality of Life in Swallowing Disorders (SWAL-QOL)" para o português do Brasil

<http://www.revistas.usp.br/tradterm/article/view/49775/53879>. Acesso em: 20 out. 2016.

Barbosa, H. G. Procedimentos técnicos da tradução: uma nova proposta. 2. ed. Campinas: Pontes, 2004.

BASSNETT, S. Estudos de tradução: fundamentos de uma disciplina. Lisboa: Fundação Calouste Gulbenkian, 2003.

Beaton, D. E. et al. "Guidelines for the process of cross-cultural adaptation of self-report measures”. In: Spine, Hagerstown, v. 25, n. 24, Dec. 2000. pp. 3186-3191.

Utensílios de cozinha. Tecla Sap, c2016. Disponível em: < http://www.teclasap.com.br/vocabulario-cozinha-utensilios-epreparo/>. Acesso em: 22 nov. 2016.

CARRARA-DE ANGelIS, E.; BANDEIRA, A. K. "Qualidade de vida em deglutição". In: Jotz, G.P.; CarRara-de Angelis, E.; Barros, A. P. B. (Ed.). Tratado de deglutição e disfagia no adulto e na criança. Rio de Janeiro, RJ: Revinter, 2009. pp. 364-368.

CASSEROLE. In: TECLA SAP, c2016. Disponível em: <http://michaelis.uol.com.br/busca?r=1\&f=1\&t=0\&palavra=casserole> . Acesso em: 16 out. 2016.

POR QUE você não deve chamar uma criança de negra? "Embaixador do Reggae" responde o motivo!. Jornal Ciência, c2015. Disponível em: <http://www.jornalciencia.com/por-que-voce-nao-deve-chamar-umacrianca-de-negra-embaixador-do-reggae-responde-o-motivo/>. Acesso em: 14 out. 2016.

CozIDo. In: MICHAELIS. UOL, c2016. Disponível em: <http://michaelis.uol.com.br/busca?id=dwOw> Acesso em: 01 nov. 2016.

FELIPINI, L. M. G. Tradução e adaptação transcultural para a língua portuguesa do Brasil dos questionários "Quality of Life in Swallowing Disorders 
FELIPINI, L. M. G. - Adaptação transcultural na tradução do questionário "Quality of Life in Swallowing Disorders (SWAL-QOL)" para o português do Brasil

(SWAL-QOL)" e "Quality of Care in Swallowing Disorders (SWAL-CARE)" para idosos com disfagia neurogênica. Tese (Doutorado) - Faculdade de Odontologia de Bauru, Universidade de São Paulo, Bauru, 2016.

Guillemin, F.; Bombardier, C.; Beaton, D. "Cross Cultural adaption of healthrelated quality of life measures: literature review and proposed guidelines". In: J Clin Epidemiol, Oxford, v. 46, n. 12, 1993. pp. 14171432.

HATJE-FAgGION, V. et al. Tradução e Cultura. Rio de Janeiro: 7Letras, 2011.

HoLIDAY. In: CAMBRIDGE Dictionary, c2016. Disponível em: <http://dictionary.cambridge.org/us/dictionary/englishportuguese/holiday>. Acesso em: 12 nov. 2016.

IBGE usa classificação de cor preta; grupo negro reúne pretos e pardos. UOL, 2013.

Disponível

em:

<http://vestibular.uol.com.br/noticias/redacao/2013/05/03/ibge-

usa-classificacao-de-cor-preta-grupo-negro-reune-pretos-e-

pardos.htm>. Acesso em: 01 nov. 2016.

INTERAÇÃO. In: MICHAELIS. UOL, c2016. Disponível em: <http://michaelis.uol.com.br/busca?r=0\&f=0\&t=0\&palavra=intera\%C3 \%A7\%C3\%A30>. Acesso em: 12 nov. 2016.

MCHORNEY, C. A. et al. "The SWAL-QOL outcomes tool for oropharyngeal dysphagia in adults: I. conceptual foundation and item development". In: Dysphagia, New York, v. 15, n. 3, 2000, pp. 115-121.

NIDA, E. Language, culture and translating. Shanghai: Foreign Language Press, 1993.

NORD, C. Text analysis in translation: theory, methodology, and didactic application of a model for translation-oriented text analysis. $2^{\mathrm{a}}$ ed. Amsterdam - New York: Rodopi, 2005. 
FELIPINI, L. M. G. - Adaptação transcultural na tradução do questionário "Quality of Life in Swallowing Disorders (SWAL-QOL)" para o português do Brasil

OtORRINOLARINGOLOGIA. Hospital Sírio-Libanês, c2016. Disponível em: <https://hospitalsiriolibanes.org.br/hospital/especialidades/centrootorrinolaringologia/Paginas/disfagia.aspx>. Acesso em: 09 nov. 2016.

ReICHENHEIM, M. E.; MORAES, C. L. "Operacionalização de adaptação transcultural de instrumentos de aferição usados em epidemiologia". In: Revista Saúde Pública, São Paulo, v. 41, n. 4, 2007. pp. 665-673.

RoBINSON, D. Construindo o tradutor. Bauru: EDUSC, 2002.

ROLE. In: CAMBRIDGE Dictionary, c2016. Disponível em: <http://dictionary.cambridge.org/us/dictionary/englishportuguese/role>. Acesso em: 12 nov. 2016.

RónAl, P. A tradução vivida. $3^{\text {a }}$ ed. Rio de Janeiro: Nova Fronteira, 1981.

Data de submissão: 19/02/2017

Data de aprovação: 08/06/2017 